\title{
Effect of Environmental Variables on Piloted Ignition
}

\author{
ARVIND ATREYA \\ Department of Mechanical Engineering \\ Michigan State University \\ East Lansing, Michigan 48824, USA
}

MAHMOOD ABU-ZAID

College of Engineering

Mutah University, Jordan

\begin{abstract}
In this paper the effect of environmental variables on piloted ignition of wood is investigated both experimentally and theoretically. The environmental variables considered are the moisture content of the solid, wind speed and its oxygen concentration and external radiation. Simultaneous measurements of weight loss rate, ignition time, sample surface temperature, oxygen depletion and production of $\mathrm{CO}_{2}, \mathrm{CO}$, total hydrocarbons, and water vapor were made. As expected, the presence of moisture delays the decomposition process and dilutes the decomposition products. The surface temperature and the evolved mass flux at ignition increased with increase in moisture content, decrease in oxygen concentration and increase in air velocity. All the ignition data are correlated according to an equation derived for surface temperature with convective and radiative heat losses. This equation reveals how the moisture content, air velocity, oxygen concentration and external radiation affect the ignition delay time. It also enables the determination of the critical incident heat flux below which piloted ignition does not occur.
\end{abstract}

Keywords: piloted ignition, environmental effects, thermal model, wood

\section{Notations:}

c specific heat

$F$ incident heat flux

$f_{S}$ heat flux entering the solid

h heat transfer coefficient / $\epsilon$

k thermal conductivity

L total surface heat loss

$\rho$ density

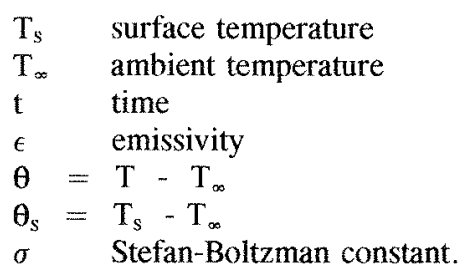

\section{INTRODUCTION}

Ignition refers to the appearance of a flame in the volatile gas stream evolved from a 
solid exposed to external heating (usually radiative). When ignition occurs in the presence of an external ignition source (such as a flame or an electrical spark) it is classified as piloted ignition. This type of ignition is important from the point-of-view of fire research since it occurs at lower critical surface temperatures and can be easily related to flame spread. Several previous investigations have been conducted on this subject. The primary emphasis of these has been on determining the time for piloted ignition as a function of external radiation and identifying the critical conditions at ignition. References $[1-4]$ serve as excellent reviews of this previous work.

For piloted ignition to occur, the solid must first decompose to produce combustible gases. These gases then mix with the surrounding air to produce a flammable mixture which is ignited by a pilot flame. This process is affected by several factors that may be classified into internal and external to the sample. External factors are the environmental variables such as the temperature, composition and the velocity of the surrounding gases and the magnitude and spectral quality of the incident radiation. Factors internal to the sample are its thermophysical and thermochemical properties and its moisture content.

Experimentally, except for the sample properties all other variables can be controlled. For hygroscopic and porous cellulosic solids, the sample moisture content is also expected to have a significant effect on the ignition process (depending on the relative humidity of the environment, wood may contain up to $30 \%$ of its oven dry weight as moisture). Thus, sample moisture content must also be carefully controlled. The importance of moisture content in relation to fire tests has long been recognized and researchers have carefully controlled the moisture content of their samples. However, few investigations have addressed its effect on ignition. Simms and Law [5] performed both auto and piloted ignition tests on samples with different moisture contents and measured the time for ignition. They concluded that increasing the moisture content increases the ignition time and determined the critical surface temperature by correlating the data according to thermal conduction theory with convective heat losses. The effect of moisture content was accounted through moisture dependent thermal properties.

In this work, a more detailed study is conducted with the objective to understand the effect of both internal and external factors on the piloted ignition process. This will assist in developing fundamental theoretical models. In particular, the effect of wind speed, oxygen mass fraction and sample moisture content on piloted ignition are investigated. Simultaneous measurements of weight loss rate, ignition time, sample surface and bottom temperatures, production of water vapor, $\mathrm{CO}_{2}, \mathrm{CO}$, total hydrocarbons, and depletion of $\mathrm{O}_{2}$ were made. These data are correlated according to an equation derived for surface temperature based on convective and radiative heat losses. This equation also enables the determination of moisture dependent thermal properties and the critical incident heat flux below which piloted ignition does not occur.

\section{APPARATUS AND PROCEDURE}

A schematic of the experimental arrangement is shown in Figure 1. The external radiation was provided by electrical radiant heaters with a maximum black-body temperature of $1200^{\circ} \mathrm{K}$. A small natural gas flame was located in the mixing layer, pointing downward as shown in Figure 1. The test samples (3"x 6"x 1.5" Douglas fir) were instrumented with thermocouples (Cr-Al, 75 $\mu \mathrm{m}$ dia.; Technique described in Ref. [6]) and then dried at $105^{\circ} \mathrm{C}$ 


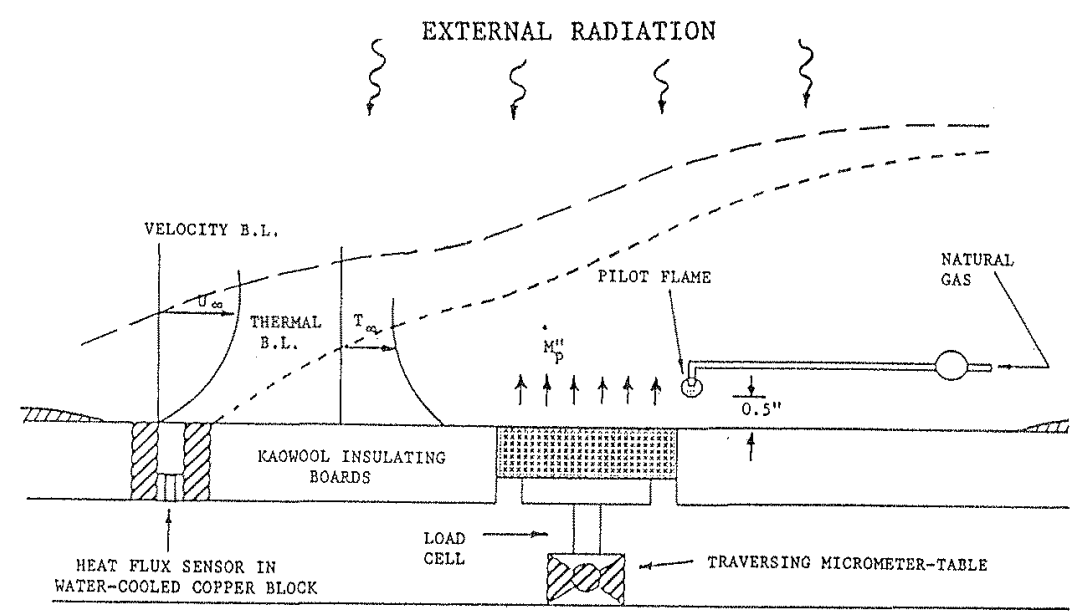

Figure 1 Schematic of the Ignition Process.

until a constant weight was achieved. They were then conditioned in a temperature and humidity controlled chamber for 5 to 6 weeks until a constant weight was obtained. The difference in the dry and wet weight was used to quantify the moisture content. The sample edges and the bottom were wrapped with aluminum foil to minimize edge effects. The air flow velocity in the tunnel and its oxygen mass fraction were treated as parameters for these experiments.

The procedure consisted of placing the instrumented sample flush with the Kaowool insulating board on a load cell (for continuous weight meaurements) and then exposing the sample to a known external radiation. This external radiation was also continuously monitored by a heat flux sensor located upstream of the sample (see Fig. 1). A calibration between the heat flux at the sensor location and the heat flux at the sample location was used to determine the incident radiation on the sample surface. A video camera was used to record the entire experiment. The ignition time was determined from this record. A computer data acquisition system was used to record the rest of the temperature and gas composition data. Continuous gas analyzers were used for gas composition measurements. This data was corrected for the analyzer response time and the transport delay time.

\section{RESULTS AND DISCUSSION}

Surface Temperature: A typical set of surface temperature measurements are shown in Figure 2. Here, the surface temperature histories of four experiments are plotted for a given incident heat flux and different moisture contents. The sharp increase in the surface temperature at the time of ignition is due to the appearance of the flame in the gas phase. Although flashes (unsustained momentary flaming) were observed prior to ignition, they are not evident in the recorded thermocouple traces because they did not occur directly above the thermocouple. As expected, the ignition time increases with decrease in heat flux and increase in moisture content. The data for ignition times and temperatures as a function of incident heat flux are summarized in Figures 3 and 4 for the effect of moisture content and in Figures 5 and 6 for the effect of air velocity and oxygen concentration. 


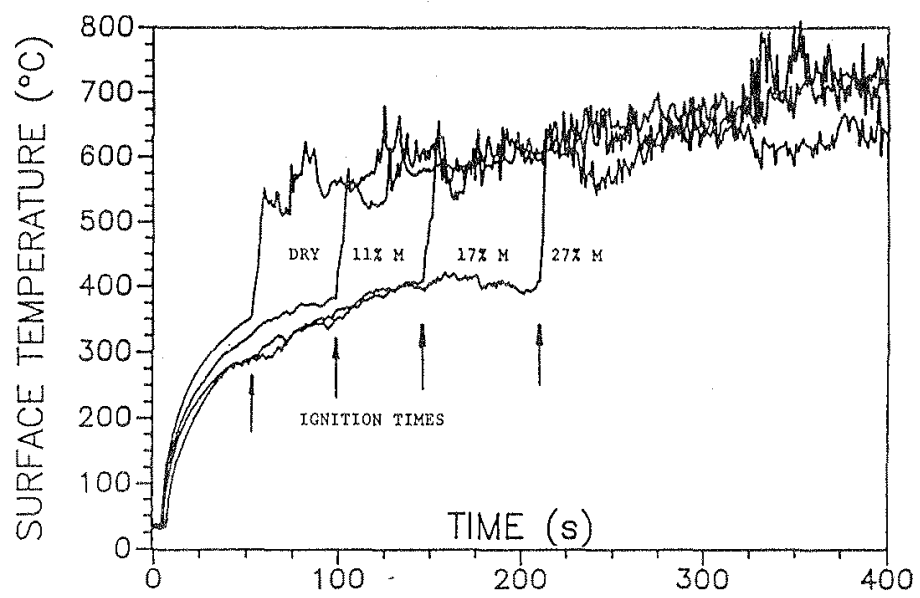

Figure 2 Effect of Moisture Content on Surface Temperature Measured at $2.65 \mathrm{~W} / \mathrm{cm}^{2}$.
Evolved Mass Flux: Measurements show that the mass flux, like $\mathrm{t} \mathrm{he} s$ u r f a c e temperature, increases sharply after ignition. Due to this sharp rise a larger error is introduced in the determination of the critical mass flux at ignition especially at high heat fluxes. However, despite this measurement error, some clear trends are discernable. These are shown in Figure 7 where the critical mass

flux at ignition for wood with different moisture contents is plotted against the incident heat flux. Note that the total evolved mass flux increases with both increase in moisture content and increase in incident heat flux. The increase with moisture content is expected but an increase with incident heat flux is puzzling. Chemical composition measurements show that the mass evolution from the sample prior to ignition is primarily due to desorption of water followed by evolution of tar (which was obtained by difference). Both these quantities are evolved at a higher rate as the incident heat flux is increased. A typical set of these measurements are shown in Figure 8. These measurements show that a substantial amount of moisture is evolved prior to ignition even for "dry wood" and its amount increases with increase in moisture content. Thus, for large heat fluxes, increased evolution of moisture or other inerts such as $\mathrm{CO}_{2}$ may be responsible for increase in the required mass flux at ignition. It is important to emphasize that the long standing belief about constant mass flux at ignition is not enforced by this set of experimental data.

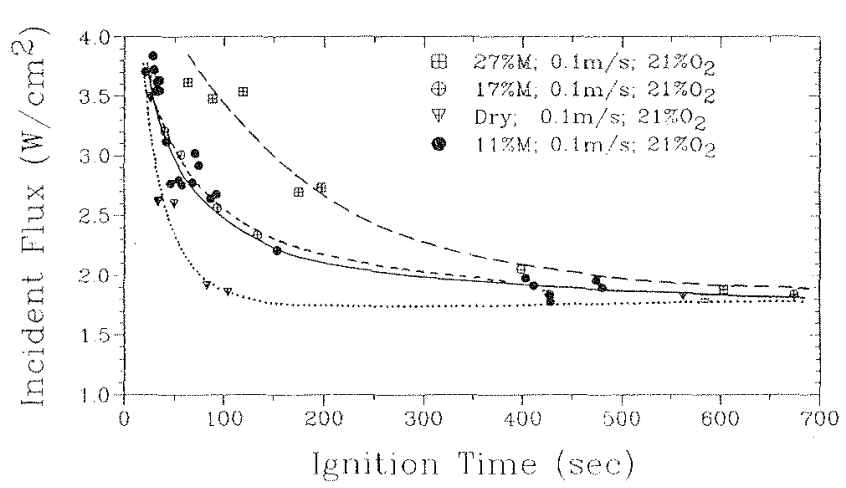

Figure 3 Effect of Moisture Content on Ignition.

Discussion: In the data summary presented in Figures $3 \& 4$ (effect of moisture content) and in Figures $5 \& 6$ (effect of air velocity and oxygen concentration), the data for $11 \%$ moisture content, 0.1 $\mathrm{m} / \mathrm{s}$ air velocity and $21 \%$ oxygen concentration is common to all sets. This is the base case and represents normal room conditions. From Figure 3 it seems that small changes in moisture content (from 


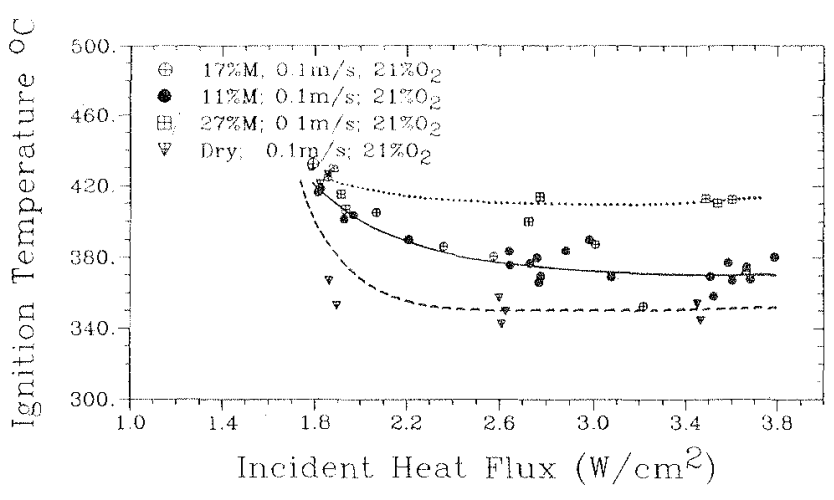

Figure 4 Effect of Moisture Content on Ignition Temperature.

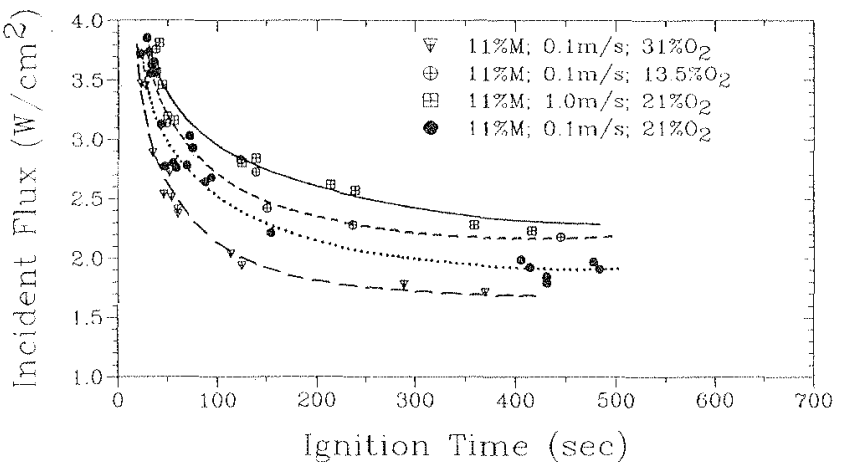

Figure 5 Effect of Air Velocity and $\mathrm{O}_{2}$ Concentration.

$11 \%$ to $17 \%$ of dry weight) fall within the experimental error and sample to sample property variations. Also, the curves collapse for low heat fluxes and seem to approach the same asymptote. This is because at low heat fluxes the sample heats slowly and dries out prior to ignition. Thus, although the time required for ignition at low heat fluxes is substantially different for different moisture contents, the asymptotic heat flux (for which ignition occurs at large times) appears to be the same. Figure 4 shows that the measured surface temperatures at ignition are higher for higher moisture contents. Also, at a given moisture content, the surface temperature at ignition increases as the heat flux decreases. For low heat fluxes the surface temperature for different moisture contents approaches the same value, indicating that most of the moisture has been evaporated and that it no longer significantly affects the piloted ignition process. The increase in ignition temperature at low heat fluxes is due to slow decomposition of the solid and the resulting build up of a low thermal conductivity char layer prior to ignition.

These results have important implications regarding theoretical modeling of piloted ignition. First, we note that at high heat fluxes the extent of solid decomposition prior to ignition is small, although moisture desorption significantly dilutes the decomposition products. However, at low heat fluxes the extent of decomposition is significant and due to long pre-heat, wood is essentially dried prior to ignition. Thus, from a modeling point-of-view the solid phase may be considered inert for high heat flux and low moisture content cases. For high heat flux and high moisture content case, the effect of moisture desorption on solid-phase heat transfer and gas-phase dilution must be included. For the low heat flux case, thermal decomposition of the solid must be included in the model for piloted ignition. 


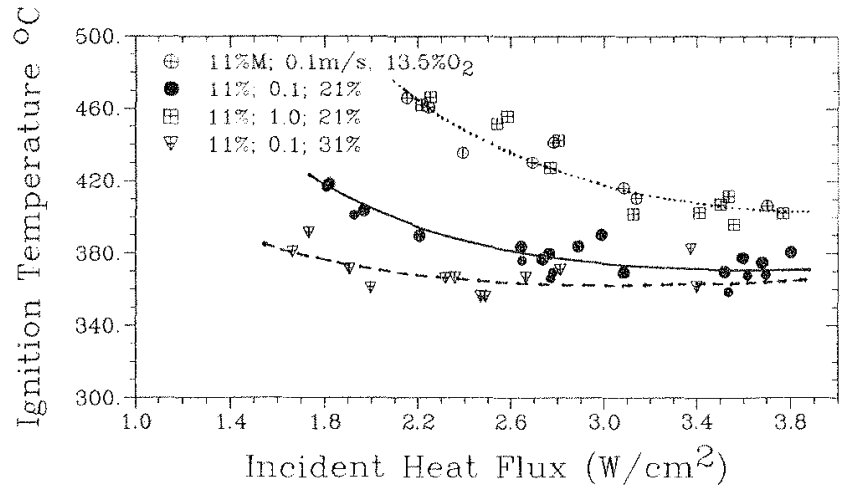

Figure 6 Effect of Air Velocity and $\mathrm{O}_{2} \%$ on Ig. Temperature.

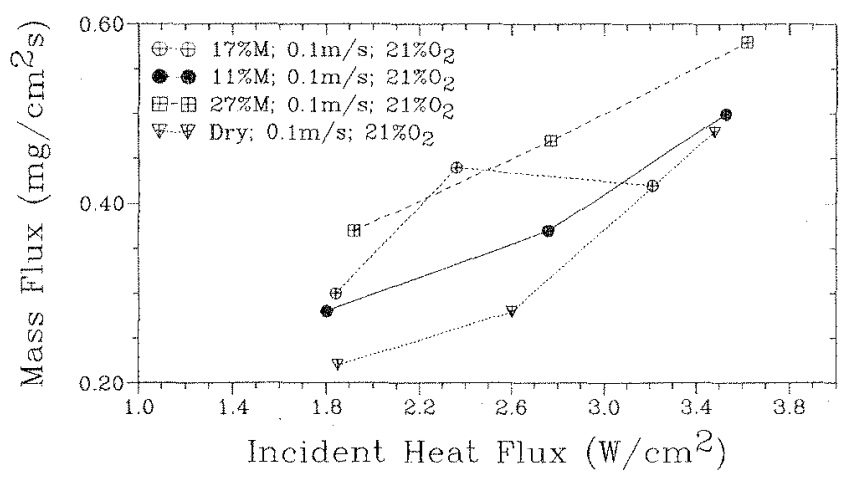

Figure 7 Effect of Moisture on Mass Flux at Ignition.
It is interesting to note that the effect of increasing the air velocity or decreasing its oxygen concentration is quite different from the effect of increasing the moisture content of the sample even though both result in an increase in the ignition delay time. This is shown in Figures 5 and 6 . In Figure 5 , the data for different air velocities and different oxygen concentrations approach different asymptotes as the heat flux is decreased; i.e. the minimum heat flux required for ignition increases with decrease in oxygen concentration and increase in air velocity. This is in contrast with Figure 3 where the asymptotic value was roughly the same regardless of the moisture content. Also, the surface temperature at ignition (Figure 6) is increased with decrease in oxygen concentration and increase in air velocity. The fact that the surface temperature does not converge to the same value at low heat fluxes (as it does for different moisture contents; Figure 4) is consistent with the fact that different asymptotes are obtained (Figure 5) at low heat fluxes. A higher surface temperature at ignition implies a higher convective and radiative heat loss which in turn gives rise to a higher minimum heat flux at ignition.

Implications of this result regarding theoretical modeling are: (i) For high oxygen concentrations and low wind speeds, ignition occurs easily (or quickly) and the required surface temperatures are lower. This implies that the extent of decomposition is small and hence the solid-phase may be treated as inert. (ii) For low oxygen concentrations and high wind speeds the ignition times and temperatures are significantly higher. Thus, considerable decomposition occurs prior to ignition and the solid may no longer be considered inert.

Correlation of Results: Although it is clear that the solid decomposes prior to ignition, it seems that the extent of decomposition under certain circumstances is small enough to 
enable the inert solid approximation. In particular, this may be a reasonable approximation under ambient conditions (11\% moisture; $0.1 \mathrm{~m} / \mathrm{s}$ air speed \& $21 \%$ oxygen) and fire level heat fluxes. Also, from the data in Figures 4 and 6 we note that the ignition temperature varies from $340^{\circ} \mathrm{C}$ to $440^{\circ} \mathrm{C}$. However, this variation is primarily due to changes in the environmental conditions (oxygen concentration, wind speed and moisture content). The variation of ignition temperature with incident heat flux is much smaller (within $\pm 20^{\circ} \mathrm{C}$ for incident heat fluxes greater than $2 \mathrm{~W} / \mathrm{cm}^{2}$ ). With these observations, essentially the solution of a one-dimensional heat conduction equation for an inert solid with convective and radiative heat losses is sought.

The simplest solution with no heat losses yields the following relationship between the incident heat flux $(F)$ and the time of ignition $(t)$ :

$$
F=\sqrt{\frac{\pi}{4} \rho c k} \quad \theta_{s} t^{1 / 2}
$$

Assuming the surface temperature $\left(\mathrm{T}_{s}\right)$ at ignition to be a constant, a linear relationship between $F$ and $t^{-1 / 2}$ is clearly evident. The role of thermal properties (which strongly depend on the moisture content) and the surface temperature at ignition (which indirectly depends on the decomposition chemistry) is also evident. However, the data in Figures 3 and 5 imply that the large time asymptotic value of the incident heat flux at ignition is due to convective and radiative heat losses (which are substantial). To determine the role of this heat loss in the piloted ignition process, an integral solution with convective and radiative heat losses is employed [7]. According to this solution the ignition time is given by:

$$
t=M\left[\frac{\theta_{s}^{2}}{2 f_{s}^{2}}+\frac{r}{\beta^{3 / 2}} \ln \left(\frac{\left(2 S \theta_{s}+r-\sqrt{\beta}\right)(r+\sqrt{\beta})}{\left(2 S \theta_{s}+r+\sqrt{\beta}\right)(r-\sqrt{\beta})}\right)-\frac{\theta_{s}\left(r+2 S \theta_{s}\right)}{\beta f_{s}}\right],
$$

$$
\text { where: } \begin{array}{r}
\quad M=\frac{2 \rho c k}{3 e^{2}} ; r=-\left(h+4 \sigma T_{\infty}^{3}\right) ; \\
S=-\frac{25}{3} \sigma T_{\infty}^{2} ; \beta=\left(r^{2}-4 S F\right) ;
\end{array}
$$

and

$$
f_{s}=-\frac{k}{\epsilon}\left(\frac{\partial \theta}{\partial x}\right)_{x=0}=\left[F-h \theta_{s}-\sigma\left(\left(\theta_{s}+T_{\infty}\right)^{4}-T_{\infty}\right)\right]
$$

Equation (2) is simplified by approximating the logarithm term and by substituting $\mathrm{f}_{\mathrm{s}}$ by (F-L). Assuming $\boldsymbol{\theta}_{\mathrm{s}}$ at ignition to be approximately constant, the following relationship between ignition time and heat flux is obtained:

$$
F=C t^{-1 / 2}+L \text {, }
$$


where: $L=h \theta_{s}+\sigma\left(\left(\theta_{s}+T_{\infty}\right)^{4}-T_{\infty}^{4}\right) ;$ and $C=\sqrt{M} \theta_{s}$.

In equation (3), $C$, which is a function of $F$ and $L$, is nearly constant at fire level heat fluxes (between 4 and $6 \mathrm{~W} / \mathrm{cm}^{2}$ ) and decreases by about $10 \%$ at $2 \mathrm{~W} / \mathrm{cm}^{2}$. Due to this systematic decrease it is necessary to emphasize that Equation (3) is an approximate version of equation (2) and $C, L$ and $\theta_{s}$ at ignition are not true constants. As seen in Figures 4 and 6 , there is a systematic variation of $\theta_{\mathrm{S}}$ with the incident heat flux.

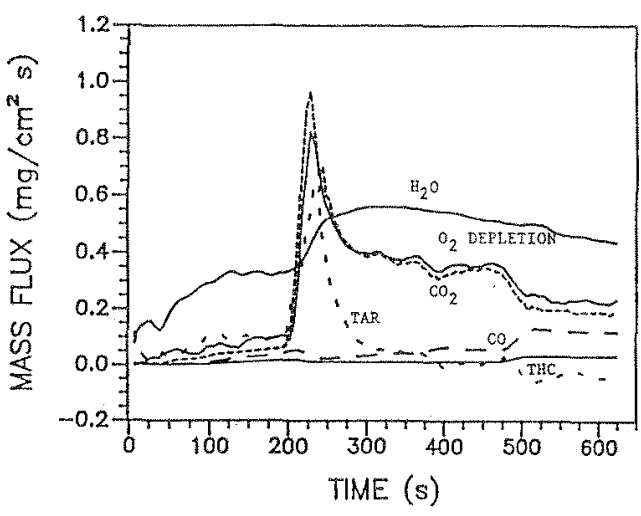

Figure 8 Evolved Gases at $2.77 \mathrm{~W} / \mathrm{cm}^{2} ; 27 \% \mathrm{M}$

A comparison of Equations (1) and (3) shows that a linear relationship between $F$ and $t$ is still valid. The primary virtue of Equation (3) lies in that it separates the effect of moisture dependent thermal properties (contained in $\mathrm{C}$; which is the slope of the straight line) from the environmentally dependent heat loss $\mathrm{L}$ (which is the intercept). The dependence on decomposition chemistry appears only through $\theta_{s}$. Since, ignition data (particularly for wood) typically has considerable scatter, a more accurate method of presentation may not be necessary. Data plotted according to Equation (3) are shown in Figures 9 and 10 along with the least square fit lines. It is important to note that the interpretation provided by Equation (3) is simple and unique. Previously [Ref. 8], it was understood that the intercept $(L)$ depends upon the chemical nature of the fuel. However, we find that it is simply the heat loss from the sample surface and can be changed by altering the environmental conditions (e.g. the air velocity which changes the convective heat loss). As the time required for ignition tends to infinity, the heat loss tends to the incident heat flux. Hence, the critical incident heat flux below which ignition is impossible, is given by $L$. This heat loss depends on the surface temperature which has been found to increase with: (i) increase in the moisture content (Figure 4), (ii)

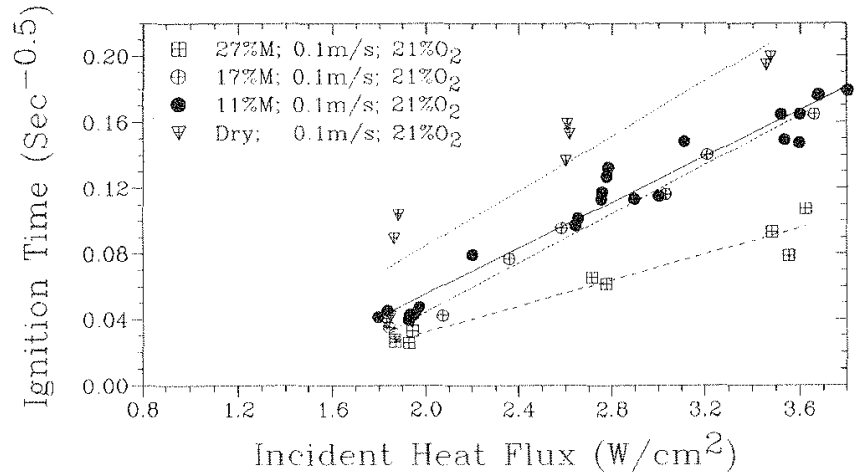

Figure 9 Correlation -- Effect of Moisture Content. increase in air velocity (Figure 6), (iii) decrease in oxygen concentration (Figure 6), (iv) decrease in incident heat flux (Figures 4 \& 6).

The measured temperatures for different moisture contents seem to converge at low incident heat fluxes (Figure 4) suggesting that the critical incident heat flux is nearly the same. Figure 3 seems 


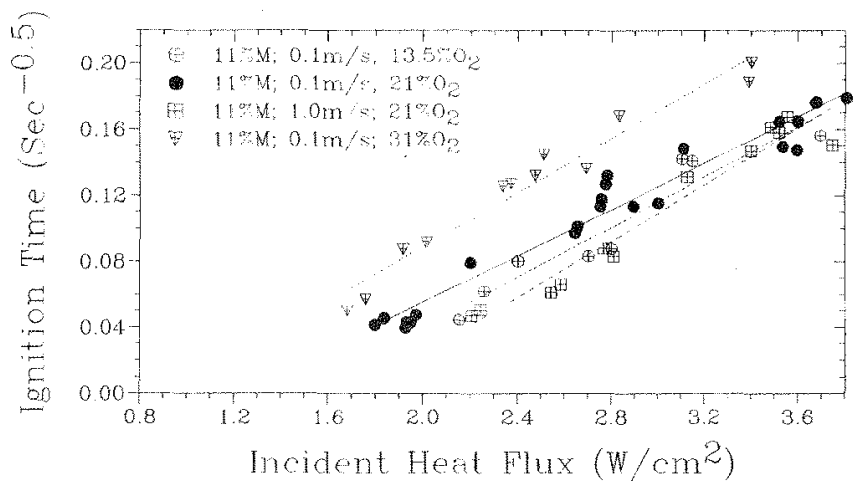

Figure 10 Correlation -- Effect of Air Velocity and $\mathrm{O}_{2} \%$.

to agree with this conclusion since the curves for different moisture contents tend to the same asymptote. However, the numerical values of ' $L$ '(from Figure 9 ; obtained by extrapolating the correlating straight lines) show a greater variation. This is because of the approximations made in reducing Equation (2) to the form of Equation (3).

These approximations include assuming $\mathrm{C}, \mathrm{L}$ and $\theta_{\mathrm{s}}$ at ignition to be constants. Similarly, Figure 5 suggests different asymptotic values of minimum incident heat flux at ignition for different air velocities and oxygen concentrations. This is consistent with Figure 6 where different surface temperatures are obtained at lower heat fluxes and Figure 10 where different intercepts of the correlating straight lines are evident.

\section{CONCLUSIONS}

This study leads to the following conclusions:

(i) The ignition time increases with decrease in incident heat flux, increase in moisture content, increase in air velocity, and decrease in oxygen concentration.

(ii) The total evolved critical mass flux at ignition increases with both increase in moisture content and increase in incident heat flux.

(iii) The surface temperature at ignition is higher for higher moisture content. For a given moisture content, the surface temperature at ignition increases as the heat flux decreases, oxygen concentration decreases, and air velocity increases.

(iv) The minimum heat flux required for ignition, is approximately the same regardless of the moisture content. However, it increases with decrease in oxygen concentration and increase in air velocity.

(v) The formulas derived to correlate the ignition data account for the thermal properties (which strongly depend on the moisture content) and the heat loss from the sample surface (which depends on the environmental conditions). They also enable the determination of critical incident heat flux below which piloted ignition does not occur.

\section{ACKNOWLEDGMENTS}

The first author is indebted to Dr. J. G. Quintiere and Dr. D. D. Evans of NIST for several helpful suggestions. This work was supported by the National Institute of Standards and Technology under the Grant No. 60NANB500578. 


\section{REFERENCES}

1. Kanury, A., "Radiative Ignition Mechanism of Solid Fuels -- A Review," Fire Research Abstracts and Reviews, Vol. 14, p 24, 1972.

2. Kashiwagi, T., "Radiative Ignition Mechanisms of Solid Fuels, " Fire Safety Journal, Vol. 3, p 185, 1981.

3. Quintiere, J., Harkleroad, M. and Walton, D., Combustion Science and Technology, Vol. 32, 67-89, 1983.

4. Simms, D., "On the Piloted Ignition of Wood by Radiation," Combustion and Elame, Vol. 7, p 253, 1963.

5. Simms, D., and Law, M., "The Ignition of Wet and Dry Wood by Radiation," Combustion and Flame, Vol. 11, p 377, 1967.

6. Atreya, A., Harkleroad, M. and Carpentier, C., "Effect of Sample Orientation on Piloted Ignition and Flame Spread," Proceedings of the First IAFSS Symposium, Hemisphere Publishing Co., 97-109, 1985.

7. Atreya, A., "Pyrolysis Ignition and Fire Spread on Horizontal Surfaces of Wood," NBS-GCR-83-449, 1983.

8. Mikkola, E., and Wichman, I., "The Thermal Ignition of Combustible Materials," Proceedings of the Eastern Section of the Combustion Institute, 1988.

9. Abu-Zaid, M., "Effect of Water on Ignition of Cellulosic Materials," NIST-GCR-89-5611, 1988. 